\title{
Classroom contexts for learning at primary and secondary school: Class size, groupings, interactions and special educational needs
}

Article

Accepted Version

Blatchford, P. and Webster, R. ORCID: https://orcid.org/00000003-1416-4439 (2018) Classroom contexts for learning at primary and secondary school: Class size, groupings, interactions and special educational needs. British Educational Research Journal, 44 (4). pp. 681-703. ISSN 1469-3518 doi: https://doi.org/10.1002/berj.3454 Available at https://centaur.reading.ac.uk/92017/

It is advisable to refer to the publisher's version if you intend to cite from the work. See Guidance on citing.

To link to this article DOI: http://dx.doi.org/10.1002/berj.3454

Publisher: Wiley

All outputs in CentAUR are protected by Intellectual Property Rights law, including copyright law. Copyright and IPR is retained by the creators or other copyright holders. Terms and conditions for use of this material are defined in the End User Agreement. 


\section{www.reading.ac.uk/centaur}

\section{CentAUR}

Central Archive at the University of Reading

Reading's research outputs online 


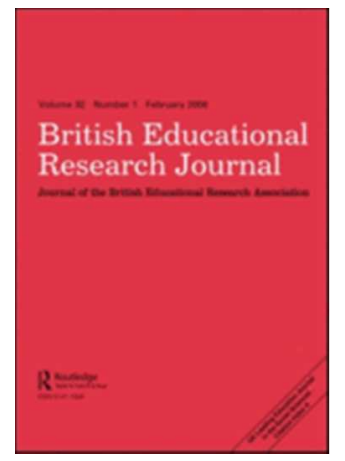

\section{Classroom contexts for learning at primary and secondary school: class size, groupings, interactions and special educational needs.}

\begin{tabular}{|r|l|}
\hline Journal: & British Educational Research Journal \\
\hline Manuscript ID & CBER-2018-0037.R1 \\
\hline Manuscript Type: & Original Paper \\
\hline Keywords: & $\begin{array}{l}\text { Observation < Research Approaches, Learning Environments < Teaching } \\
\text { Processes, Classroom < Formal Learning Contexts, Social Interaction < } \\
\text { Interaction }\end{array}$ \\
\hline \multirow{5}{*}{ Abstract: } & $\begin{array}{l}\text { The inclusion of pupils with special educational needs and disabilities } \\
\text { (SEND) in mainstream schools can result in difficult decisions regarding } \\
\text { classroom organisation and management. The premise of this paper is that } \\
\text { these are likely to be affected by the classroom context, specifically, the } \\
\text { number of pupils in the class, the size and composition of groups and } \\
\text { classes, and the presence of additional adults, but that there is very little } \\
\text { systematic information on these features. A systematic observation study } \\
\text { was conducted involving 48 pupils at Year } 5 \text { (9-10 years) and } 49 \text { pupils at } \\
\text { Year } 9 \text { (13-14 years) with Statements of SEND, along with 115 comparison } \\
\text { pupils at Year 5 and 112 at Year } 9 \text { who were typically developing. There } \\
\text { were nearly 70,000 observations (data points) in total. Results showed that } \\
\text { pupils in Year } 5 \text { with SEN were being taught in larger classes than at Year } \\
\text { 9, and that, compared to typically developing pupils, they were much more } \\
\text { likely to be separately taught in small low attaining groups at Year } 5 \text { and } \\
\text { small low attaining classes (sets) at secondary. The study raises worrying } \\
\text { questions about the appropriateness of classroom contexts for pupils with } \\
\text { SEND and the heavy reliance on Teaching Assistants. }\end{array}$ \\
\hline
\end{tabular}


Table 1. Pupils with Statements: Year 5

\begin{tabular}{|c|c|c|c|c|c|c|c|c|c|c|c|c|c|c|}
\hline \multirow[b]{3}{*}{$\begin{array}{l}\text { Moderate } \\
\text { learning } \\
\text { difficulties }\end{array}$} & \multicolumn{4}{|c|}{ Gender } & \multicolumn{4}{|c|}{ Ethnicity } & \multirow{2}{*}{\multicolumn{2}{|c|}{ EAL }} & \multirow{2}{*}{\multicolumn{2}{|c|}{ FSM }} & \multirow{2}{*}{\multicolumn{2}{|c|}{$\begin{array}{l}\text { Total } \\
\text { pupils }\end{array}$}} \\
\hline & \multicolumn{2}{|c|}{ Boy } & \multicolumn{2}{|c|}{ Girl } & \multicolumn{2}{|c|}{ White } & \multicolumn{2}{|c|}{ Other } & & & & & & \\
\hline & 18 & $50 \%$ & 11 & $92 \%$ & 24 & $65 \%$ & 5 & $45 \%$ & 3 & $\begin{array}{c}100 \\
\%\end{array}$ & 10 & $45 \%$ & 29 & $60 \%$ \\
\hline $\begin{array}{l}\text { Behavioural, } \\
\text { emotional or } \\
\text { social difficulties; } \\
\text { or composite } \\
\text { needs }\end{array}$ & 18 & $50 \%$ & 1 & $8 \%$ & 13 & $35 \%$ & 6 & $54 \%$ & 0 & $0 \%$ & 12 & $54 \%$ & 19 & $40 \%$ \\
\hline Total & 36 & $75 \%$ & 12 & $25 \%$ & 37 & $77 \%$ & 11 & $23 \%$ & 3 & $6 \%$ & 22 & $46 \%$ & 48 & $\begin{array}{c}100 \\
\%\end{array}$ \\
\hline
\end{tabular}

Table 2. Pupils with Statements/EHCPs: Year 9

\begin{tabular}{|c|c|c|c|c|c|c|c|c|c|c|c|c|c|c|}
\hline \multirow{3}{*}{\begin{tabular}{|l|}
$\begin{array}{l}\text { Cognition and } \\
\text { learning }\end{array}$ \\
\end{tabular}} & \multicolumn{4}{|c|}{ Gender } & \multicolumn{4}{|c|}{ Ethnicity } & \multirow{2}{*}{\multicolumn{2}{|c|}{ EAL }} & \multirow{2}{*}{\multicolumn{2}{|c|}{ FSM }} & \multirow{2}{*}{\multicolumn{2}{|c|}{$\begin{array}{c}\text { Total } \\
\text { pupils }\end{array}$}} \\
\hline & \multicolumn{2}{|c|}{ Boy } & \multicolumn{2}{|c|}{ Girl } & \multicolumn{2}{|c|}{ White } & \multicolumn{2}{|c|}{ Other } & & & & & & \\
\hline & 28 & $82 \%$ & 12 & $80 \%$ & 32 & $80 \%$ & 8 & $89 \%$ & 5 & $83 \%$ & 12 & $80 \%$ & 40 & $82 \%$ \\
\hline $\begin{array}{l}\text { Other primary } \\
\text { need }\end{array}$ & 6 & $18 \%$ & 3 & $20 \%$ & 8 & $21 \%$ & 1 & $11 \%$ & 1 & $17 \%$ & 3 & $20 \%$ & 9 & $18 \%$ \\
\hline Total & 34 & $69 \%$ & 15 & $31 \%$ & 40 & $82 \%$ & 9 & $18 \%$ & 6 & $12 \%$ & 15 & $31 \%$ & 49 & $\begin{array}{c}100 \\
\%\end{array}$ \\
\hline
\end{tabular}

Note: Communication and interaction difficulties (4 pupils); social, emotional and mental health difficulties (3 pupils); and sensory and/or physical needs (2 pupils). 
Table 3. Curriculum subject by attainment group: Year 5

\begin{tabular}{|c|c|c|c|c|c|c|c|c|c|c|c|c|c|c|c|c|}
\hline & \multicolumn{6}{|c|}{ Comparison } & \multicolumn{10}{|c|}{ Statement } \\
\hline & \multicolumn{2}{|c|}{ Average } & \multicolumn{2}{|c|}{ Mixed } & \multicolumn{2}{|c|}{ Total } & \multicolumn{2}{|c|}{ High } & \multicolumn{2}{|c|}{ Average } & \multicolumn{2}{|c|}{ Low } & \multicolumn{2}{|c|}{ Mixed } & \multicolumn{2}{|c|}{ Total } \\
\hline English & 49 & $7 \%$ & 650 & $93 \%$ & 699 & $26 \%$ & 55 & $1 \%$ & 38 & $1 \%$ & 1,252 & $32 \%$ & 2,580 & $66 \%$ & 3,925 & $23 \%$ \\
\hline Maths & 67 & $20 \%$ & 264 & $80 \%$ & 331 & $23 \%$ & 70 & $3 \%$ & 211 & $8 \%$ & 1,447 & $52 \%$ & 1,055 & $38 \%$ & 2,783 & $18 \%$ \\
\hline Science & 12 & $3 \%$ & 362 & $97 \%$ & 374 & $20 \%$ & 0 & $0 \%$ & 0 & $0 \%$ & 142 & $9 \%$ & 1,359 & $91 \%$ & 1,501 & $13 \%$ \\
\hline Hum'ties & 4 & $1 \%$ & 370 & $99 \%$ & 374 & $15 \%$ & 0 & $0 \%$ & 0 & $0 \%$ & 9 & $1 \%$ & 1,431 & $99 \%$ & 1,440 & $13 \%$ \\
\hline MFL & 0 & $0 \%$ & 61 & $100 \%$ & 61 & $7 \%$ & 0 & $0 \%$ & 0 & $0 \%$ & 0 & $0 \%$ & 223 & $100 \%$ & 223 & $6 \%$ \\
\hline Arts/DT* & 0 & $0 \%$ & 219 & $100 \%$ & 219 & $3 \%$ & 0 & $0 \%$ & 0 & $0 \%$ & 27 & $3 \%$ & 937 & $97 \%$ & 964 & $10 \%$ \\
\hline Other & 0 & $0 \%$ & 407 & $100 \%$ & 407 & $3 \%$ & 0 & $0 \%$ & 0 & $0 \%$ & 170 & $9 \%$ & 1,820 & $91 \%$ & 1,990 & $9 \%$ \\
\hline Total & 132 & $5 \%$ & 2,333 & $95 \%$ & 2,465 & $100 \%$ & 125 & $1 \%$ & 249 & $2 \%$ & 3,047 & $24 \%$ & 9,405 & $73 \%$ & 12,826 & $100 \%$ \\
\hline
\end{tabular}

* Art/music/drama/design and technology/ICT 
Table 4. Curriculum subject by attainment group: Year 9

\begin{tabular}{|c|c|c|c|c|c|c|c|c|c|c|c|c|c|c|c|c|}
\hline & \multicolumn{6}{|c|}{ Comparison } & \multicolumn{10}{|c|}{ Statement/EHCPs } \\
\hline & \multicolumn{2}{|c|}{ Average } & \multicolumn{2}{|c|}{ Mixed } & \multicolumn{2}{|c|}{ Total } & \multicolumn{2}{|c|}{ High } & \multicolumn{2}{|c|}{ Average } & \multicolumn{2}{|c|}{ Low } & \multicolumn{2}{|c|}{ Mixed } & \multicolumn{2}{|c|}{ Total } \\
\hline English & 1,341 & $84 \%$ & 255 & $16 \%$ & 1,596 & $26 \%$ & 0 & $0 \%$ & 199 & $3 \%$ & 5,377 & $85 \%$ & 778 & $12 \%$ & 6,354 & $23 \%$ \\
\hline Maths & 1,378 & $99 \%$ & 11 & $1 \%$ & 1,389 & $23 \%$ & 0 & $0 \%$ & 546 & $11 \%$ & 4,076 & $84 \%$ & 213 & $4 \%$ & 4,835 & $18 \%$ \\
\hline Science & 1,193 & $100 \%$ & 0 & $0 \%$ & 1,193 & $20 \%$ & 0 & $0 \%$ & 400 & $11 \%$ & 3,023 & $83 \%$ & 217 & $6 \%$ & 3,640 & $13 \%$ \\
\hline Hum'ties & 468 & $50 \%$ & 460 & $50 \%$ & 928 & $15 \%$ & 54 & $2 \%$ & 151 & $4 \%$ & 1,595 & $44 \%$ & 1,792 & $50 \%$ & 3,592 & $13 \%$ \\
\hline$M F L$ & 236 & $57 \%$ & 177 & $43 \%$ & 413 & $7 \%$ & 0 & $0 \%$ & 46 & $3 \%$ & 1,188 & $77 \%$ & 300 & $20 \%$ & 1,534 & $6 \%$ \\
\hline Arts & 53 & $30 \%$ & 121 & $70 \%$ & 174 & $3 \%$ & 0 & $0 \%$ & 44 & $2 \%$ & 781 & $27 \%$ & 2,043 & $71 \%$ & 2,868 & $10 \%$ \\
\hline$D \& T / I C T$ & 109 & $51 \%$ & 106 & $49 \%$ & 215 & $4 \%$ & 0 & $0 \%$ & 98 & $4 \%$ & 624 & $28 \%$ & 1,515 & $68 \%$ & 2,237 & $8 \%$ \\
\hline Other & 105 & $63 \%$ & 61 & $37 \%$ & 166 & $3 \%$ & 0 & $0 \%$ & 64 & $3 \%$ & 940 & $38 \%$ & 1,464 & $59 \%$ & 2,468 & $9 \%$ \\
\hline Total & 4,883 & $80 \%$ & 1,191 & $20 \%$ & 6,074 & $100 \%$ & 54 & $<1 \%$ & 1,548 & $6 \%$ & $\begin{array}{c}17,60 \\
4\end{array}$ & $64 \%$ & 8,322 & $30 \%$ & $\begin{array}{c}27,52 \\
8\end{array}$ & $100 \%$ \\
\hline
\end{tabular}

Table 5. Class size by attainment group

\begin{tabular}{|r|c|c|c|c|c|c|}
\hline & \multicolumn{2}{|c|}{ Year 5 } & \multicolumn{2}{c|}{ Year 9 } & \multicolumn{2}{c|}{ Year 9 } \\
\hline & \multicolumn{2}{|c|}{ All pupils } & \multicolumn{2}{c|}{ Comparison } & \multicolumn{2}{c|}{ Statement } \\
\hline$<4$ & 0 & $0 \%$ & 0 & $0 \%$ & 33 & $1 \%$ \\
\hline $5-8$ & 0 & $0 \%$ & 0 & $0 \%$ & 451 & $9 \%$ \\
\hline $9-12$ & 26 & $1 \%$ & 0 & $0 \%$ & 1,325 & $28 \%$ \\
\hline $13-16$ & 55 & $2 \%$ & 124 & $11 \%$ & 853 & $18 \%$ \\
\hline $17-20$ & 303 & $10 \%$ & 222 & $20 \%$ & 838 & $18 \%$ \\
\hline $21-24$ & 841 & $29 \%$ & 245 & $22 \%$ & 730 & $15 \%$ \\
\hline $25-28$ & 1,092 & $37 \%$ & 386 & $34 \%$ & 384 & $8 \%$ \\
\hline $29-32$ & 415 & $14 \%$ & 147 & $13 \%$ & 147 & $3 \%$ \\
\hline $33+$ & 217 & $7 \%$ & 0 & $0 \%$ & 0 & $0 \%$ \\
\hline Total & 2,949 & $100 \%$ & 1,124 & $100 \%$ & 4,761 & $100 \%$ \\
\hline
\end{tabular}


Table 6. Class size by attainment group: Year 9

\begin{tabular}{|r|c|c|c|c|c|c|c|c|c|c|c|c|c|c|c|c|}
\hline & \multicolumn{9}{|c|}{ Comparison } & \multicolumn{7}{c|}{ Statement } \\
\hline & \multicolumn{2}{|c|}{ Average } & \multicolumn{2}{|c|}{ Mixed } & \multicolumn{2}{|c|}{ Total } & \multicolumn{2}{c|}{ High } & \multicolumn{2}{c|}{ Average } & \multicolumn{2}{c|}{ Low } & \multicolumn{2}{c|}{ Mixed } & \multicolumn{2}{c|}{ Total } \\
\hline$<4$ & 0 & $0 \%$ & 0 & $0 \%$ & 0 & $0 \%$ & 0 & $0 \%$ & 0 & $0 \%$ & 23 & $1 \%$ & 10 & $1 \%$ & 33 & $1 \%$ \\
\hline $5-8$ & 0 & $0 \%$ & 0 & $0 \%$ & 0 & $0 \%$ & 0 & $0 \%$ & 0 & $0 \%$ & 437 & $14 \%$ & 14 & $1 \%$ & 451 & $9 \%$ \\
\hline $9-12$ & 0 & $0 \%$ & 0 & $0 \%$ & 0 & $0 \%$ & 0 & $0 \%$ & 9 & $3 \%$ & 1,216 & $40 \%$ & 100 & $7 \%$ & 1,325 & $28 \%$ \\
\hline $13-16$ & 81 & $9 \%$ & 43 & $18 \%$ & 124 & $11 \%$ & 0 & $0 \%$ & 7 & $3 \%$ & 669 & $22 \%$ & 177 & $12 \%$ & 853 & $18 \%$ \\
\hline $17-20$ & 166 & $19 \%$ & 56 & $24 \%$ & 222 & $20 \%$ & 0 & $0 \%$ & 57 & $22 \%$ & 470 & $15 \%$ & 311 & $21 \%$ & 838 & $18 \%$ \\
\hline $21-24$ & 192 & $22 \%$ & 53 & $23 \%$ & 245 & $22 \%$ & 0 & $0 \%$ & 151 & $59 \%$ & 196 & $6 \%$ & 383 & $26 \%$ & 730 & $15 \%$ \\
\hline $25-28$ & 325 & $36 \%$ & 61 & $26 \%$ & 386 & $34 \%$ & 0 & $0 \%$ & 26 & $10 \%$ & 24 & $1 \%$ & 334 & $23 \%$ & 384 & $8 \%$ \\
\hline $29-32$ & 127 & $14 \%$ & 20 & $9 \%$ & 147 & $13 \%$ & 0 & $0 \%$ & 8 & $3 \%$ & 15 & $0 \%$ & 124 & $9 \%$ & 147 & $3 \%$ \\
\hline Total & 891 & $80 \%$ & 233 & $20 \%$ & 1,124 & $100 \%$ & 0 & $0 \%$ & 258 & $5 \%$ & 3,050 & $64 \%$ & 1,453 & $31 \%$ & 4,761 & $100 \%$ \\
\hline
\end{tabular}


Table 7. Observations of interaction type, social mode and location at Year 5 and 9

\begin{tabular}{|c|c|c|c|c|c|c|c|c|c|c|c|c|c|}
\hline & & \multicolumn{8}{|c|}{ Year 5} & \multicolumn{4}{|c|}{ Year 9} \\
\hline & & \multirow{2}{*}{\multicolumn{2}{|c|}{$\begin{array}{c}\text { Comparison } \\
\text { In class }\end{array}$}} & \multicolumn{6}{|c|}{ Statement } & \multirow{2}{*}{\multicolumn{2}{|c|}{$\begin{array}{c}\text { Comparison } \\
\text { In class }\end{array}$}} & \multirow{2}{*}{\multicolumn{2}{|c|}{$\begin{array}{c}\begin{array}{c}\text { Statement/ } \\
\text { EHCP }\end{array} \\
\text { Total }\end{array}$}} \\
\hline & & & & $\ln c$ & lass & Out of cla & $S S \& A R P$ & To & & & & & \\
\hline \multirow{4}{*}{ 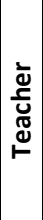 } & Part of class & 1,489 & $35 \%$ & 6,659 & $22 \%$ & 429 & $1 \%$ & 7,085 & $23 \%$ & 2,676 & $43 \%$ & 9,213 & $35 \%$ \\
\hline & Part of group & 79 & $2 \%$ & 454 & $1 \%$ & 759 & $2 \%$ & 1,213 & $4 \%$ & 96 & $2 \%$ & 719 & $3 \%$ \\
\hline & One-to-one & 109 & $3 \%$ & 915 & $3 \%$ & 342 & $1 \%$ & 1,257 & $4 \%$ & 146 & $2 \%$ & 1,574 & $6 \%$ \\
\hline & Total & $(1,677)$ & $(40 \%)$ & $(8,028)$ & $(26 \%)$ & $(1,527)$ & (5\%) & $(9,555)$ & $(31 \%)$ & $(2,918)$ & $(47 \%)$ & $(11,506)$ & $(43 \%)$ \\
\hline \multirow{4}{*}{$\leftleftarrows$} & Part of class & 42 & $1 \%$ & 609 & $2 \%$ & 15 & $<1 \%$ & 624 & $2 \%$ & 1 & $<1 \%$ & 351 & $1 \%$ \\
\hline & Part of group & 26 & $1 \%$ & 1,054 & $3 \%$ & 924 & $3 \%$ & 1,978 & $6 \%$ & 7 & $<1 \%$ & 791 & $3 \%$ \\
\hline & One-to-one & 25 & $1 \%$ & 2,857 & $9 \%$ & 2,984 & $10 \%$ & 5,841 & $19 \%$ & 25 & $<1 \%$ & 3,674 & $14 \%$ \\
\hline & Total & (93) & $(2 \%)$ & $(4,520)$ & $(15 \%)$ & $(3,923)$ & $(13 \%)$ & $(8,443)$ & $(27 \%)$ & (33) & $(1 \%)$ & $(4,816)$ & (18\%) \\
\hline \multicolumn{2}{|c|}{ Peer interaction } & 1,361 & $32 \%$ & 4,114 & $13 \%$ & 1,396 & $5 \%$ & 5,510 & $18 \%$ & 1,672 & $27 \%$ & 4,166 & $16 \%$ \\
\hline \multicolumn{2}{|c|}{ No interaction } & 1,102 & $26 \%$ & 5,856 & $19 \%$ & 1,418 & $5 \%$ & 7,274 & $24 \%$ & 1,605 & $26 \%$ & 6,197 & $23 \%$ \\
\hline \multicolumn{2}{|c|}{ Total interaction } & 4,233 & $100 \%$ & 22,518 & $73 \%$ & 8,264 & $27 \%$ & 30,782 & $100 \%$ & 6,228 & $100 \%$ & 26,685 & $100 \%$ \\
\hline
\end{tabular}

Note: $4 \%$ of observations of pupils with Statements/EHCPs in Year 9 were made outside the classroom 


\title{
Classroom contexts for learning at primary and secondary school: class size, groupings, interactions and special educational needs.
}

\author{
Author $\mathbf{1}^{\mathrm{i}}$ and Author 2 \\ UCL Institute of Education
}

\begin{abstract}
The inclusion of pupils with special educational needs and disabilities (SEND) in mainstream schools can result in difficult decisions regarding classroom organisation and management. The premise of this paper is that these are likely to be affected by the classroom context, specifically, the number of pupils in the class, the size and composition of groups and classes, and the presence of additional adults, but that there is very little systematic information on these features. A systematic observation study was conducted involving 48 pupils at Year 5 (9-10 years) and 49 pupils at Year 9 (13-14 years) with Statements of SEND, along with 115 comparison pupils at Year 5 and 112 at Year 9 who were typically developing. There were nearly 70,000 observations (data points) in total. Results showed that pupils in Year 5 with SEN were being taught in larger classes than at Year 9, and that, compared to typically developing pupils, they were much more likely to be separately taught in small low attaining groups at Year 5 and small low attaining classes (sets) at secondary. The study raises worrying questions about the appropriateness of classroom contexts for pupils with SEND and the heavy reliance on Teaching Assistants.
\end{abstract}

\section{Key words}

Class size, Special Educational Needs, within class groupings, ability grouping

\section{Introduction}

In most countries across the world there is an ongoing debate about the best ways of educating pupils with diverse abilities. There is a common aspiration to ensure that all pupils receive a high-quality education with opportunities to learn, and, in many countries, there are policies of inclusion in which pupils with special educational needs and disabilities (SEND) are, as far as possible, educated in mainstream schools. This is an admirable aim, but it can result in difficult decisions regarding classroom organisation and classroom management. The premise of this paper is that these are likely to be affected by features of the classroom context, such as the number of pupils in the class, the size and composition of within class groups, and the presence of additional adults, but that there is very little systematic information on these features.

This paper is concerned with the group of pupils with SEND in mainstream schools who tend to have difficulties in accessing everyday classroom learning experiences. In England, children and young people with complex needs undergo statutory assessment, and have their needs and provision set out in a legal document called an Education, Health and Care Plan (EHCP) or a Statement. In 2016, 236,805 pupils had a Statement or EHCP, equal to $2.8 \%$ of the total pupil population. The educational outlook for such pupils with SEN is troubling. Those with SEND are nine times more likely to receive a school exclusion, seven times less likely to find paid employment, twice as likely to live in poverty, four times more likely to have mental health problems, and they are likely to die at least 15 years younger (O'Brien, 2016). The Cambridge Primary Review concluded that 'there is an urgency about providing educational and social support for particular children in difficulty which 
cannot wait for primary education - or society as a whole - to become more equitable and inclusive' (Alexander, 2009).

There is nothing new about a concern with the education of pupils with learning and behavioural difficulties. There has, for example, been a good deal of interest in appropriate pedagogies for pupils with SEND (Gersten \& Edwards Santoro, 2007), and school policies of inclusion and school leadership (Ainscow, 2007). But we argue that the successful education of pupils with SEN is affected by the everyday classroom contexts, such as class and grouping sizes, within which they spend their school days. It is important to know more about these educational contexts within which teachers have to work and which influence the effectiveness of pedagogical strategies.

Research on classroom processes and effective teaching has tended to assume an underlying direct model, in the sense that the focus has been on the direct association between teaching and pupils' attainments (see Creemers, 1994; Kyriakou, 2009; Muijs \& Reynolds, 2011). But teachers in classrooms do not meet pupils individually, out of context, and they will necessarily have to adapt to features of the classroom context. In line with Bronfenbrenner's (1979) model, this paper is informed by a conceptualisation of educational processes taking place in hierarchically organised contexts, though within the 'microsystem' of the school, there will be smaller contexts, especially the classroom, which have distinct relationships, rules and dynamics. In addition, contexts are nested within classrooms, as in the case of smaller groups organised within the class. An early conception of the immediate environment as a factor in everyday behaviour was the ecological psychology of Barker and colleagues (Barker \& Gump, 1964; Kounin \& Gump, 1974). When applied to classrooms, the basic idea is within classroom contexts (called 'behaviour settings') have forces or 'signals' different to other contexts, which pull events and participants along with them (Kounin \& Gump, 1974).

In this paper we look at the experience of pupils with SEND, in comparison with typically-developing pupils, in terms of three features of the classroom learning environment: class size, the ability mix of teaching groups, and interactions with teachers and additional adults (Teaching Assistants - TAs).

\section{Class size}

Perhaps the most basic feature of any classroom across the world is that it comprises a certain number of pupils and usually just one teacher. This basic feature is often taken for granted, but it is likely to affect the types of interactions and relationships that develop, and the nature of learning experienced by pupils and teachers.

Class sizes vary between countries. In the UK, class sizes are relatively large - the fourth largest in the OECD. The UK is unusual across OECD countries in that the number of pupils per class tends to decrease between primary and lower secondary education (average of 27 at primary and 20 at lower secondary). For many years, the size of classes in schools have been the subject of intense debate, and this is not surprising given they are likely to have important implications for educational planning and resourcing, and ultimately pupil learning. There have been some reviews of the literature on class size effects (Biddle \& Berliner,2002; Author 1, 2012; Ehrenberg, Brewer, Gamoran \& Willms,2001; Finn, Pannozzo \& Achilles,2003), but there are surprisingly few dedicated studies and knowledge about class size effects and mediating classroom processes is still relatively limited. In this paper we extend our previous research (e.g., Author 1, Bassett, Goldstein \& Martin 2003b; Author 1, Bassett \& Brown, 2011; Author 1, Moriarty, Edmonds \& Martin, 2002; Author 1, Baines, Kutnick, \& Martin, 2001) by examining the connections between class size, classroom contexts and SEND. 
It seems likely that pupils with SEND will be particularly affected by the size of the class. One of the justifications of small classes is the hope that they will help those with most ground to make up academically receive more individual attention and be better able to concentrate (Finn et al., 2003). As far as we know there is little information available on how pupils with SEND in reality experience class size and how this compares with typically-developing pupils.

Although class size - the number of pupils in a class - might seem to be obvious, there are in practice a number of complications in reliably measuring it. Importantly, the number of children actually in the class for a given lesson may be different to the number according to the class register; children may be away, for example, and the extent of absences may vary from school to school. Class size at secondary school may be difficult to define and compare because pupils often attend several different classes, depending on the subject area, with sometimes varying class sizes. Moreover, over the course of the school year the number of children may change. The difference between the register number and the actual number is likely to be particularly marked for pupils with SEND because they are more likely to be absent and taken out of the class for interventions and are not always engaged in class activities (Author 2 \& Author 1, 2014). In order to be examined reliably, it is therefore important for a measure of class size to be closely tied to a child's experience on a lesson by lesson basis. This we call the 'experienced' class size in contrast to the class size on the register. This kind of information is not collected by Government and one aim of this study is to collect this more reliable information in order to compare the experienced class size of SEND vs. typically-developing pupils and primary vs. and secondary school. Without being clear about what pupils experience, we cannot make effective judgments about which provisions work best.

2.The composition of within class groups and class level sets in terms of ability or attainment mix

The way pupils are grouped for learning often varies between primary and secondary schools in England. At primary level, pupils are likely to be in the same class for much of the school day, often with the same teacher, and a main classroom context is the within class group within which pupils spend much of the learning time. In many Western countries classes are organized into separate groups of children.

The benefits or disadvantages of different within class grouping practices has aroused a good deal of comment and research in Britain and elsewhere. 'Progressive' primary education practices, including small group work, championed by the Plowden Report (CACE, 1967) were long ago criticised as being ineffective (Alexander, Rose \& Woodhead, 1992). Despite these pressures, research going back many years (Baines, Author 1 \& Kutnick, 2003; Galton, Hargreaves, Comber, Wall \& Pell, 1999; Pollard, Broadfoot, Croll, Osborn \& Abbott,1994) has shown the popularity of organising within class groups on the basis of similar attainment or 'ability' levels. Secondary schools tend to be different in that they use class-level grouping by attainment for particular subjects. This is referred to as 'setting' in the UK, and is different to grouping of pupils into classes by attainment levels for all subjects (referred to as 'streaming' or 'tracking'), which was once common in the UK.

The use of similar attainment groupings is therefore common but the rationale behind it is rather implicit. It is presumably done on the assumption that teaching becomes more effective or efficient with a narrower range of attainment in a group or class, but the evidence in its favour is hard to find. While homogeneous grouping has been shown to have some benefit for higher-attaining pupils, it can be detrimental to the learning and self-confidence of average- and lower-attaining pupils (Francis et al., 2017a; Ireson et al., 2002; Kutnick et al., 2005; Peacock, 2016; Taylor et al., 2016).

As far as we know there is very little available information on the experiences of pupils with SEND vs typically-developing pupils in terms of the attainment mix of within class groupings (primary) and 
classes (secondary). This information is important, however, because these are the most immediate classroom contexts for learning.

\section{The amount and type of interaction with teachers, TAs and peers}

The third classroom contextual feature examined in this paper is the interactive context provided by the people there: teachers, additional adults, and peers. The trend for more pupils with SEND being included in mainstream settings has been accompanied by an increase in the numbers of classroomand pupil-based support staff, referred to collectively throughout this paper as TAs. The number of full-time equivalent (FTE) TAs in mainstream schools in England has more than trebled since 2000 (DfE, 2016b). Currently TAs comprise $27 \%$ of the school workforce in England: $35 \%$ of the nursery and primary school workforce; $14 \%$ of the secondary school workforce.

School leaders report that one of the main reasons for the increase in TAs is that inclusion policies would be impossible to implement without them (Author 1 et al., 2012). Author 1 et al. (2012) found that TAs have a predominantly pedagogical role, and spend much of their time supporting pupils with SEND and lower-attaining pupils. Though this allows hard-pressed teachers to devote time to the rest of the class, in the knowledge that pupils in most need are given potentially valuable individual attention by TAs, Author 1 et al. (2012) found there was a negative relationship between the amount of TA support received and the progress made by pupils, in particular, those with the highest levels of SEND (Author 2 et al., 2010), and this was not explained by pupil characteristics, such as prior attainment. This finding was consistent over primary and secondary settings.

The research just reported looked through the lens of the TAs in schools. The research reported in this paper had as its main rationale the need to examine directly, and in detail, the moment by moment experiences of pupils with SEND, in terms of their time with teachers and TAs, across primary and secondary schools. We further examined whether interactions were part of the whole class, part of a group or one to one.

Rationale of the research approach

There is surprisingly little systematic research on some of the more fundamental organisational aspects of the support in place for pupils with SEND. One of the most authoritative sources available (Florian, 2009), does not have any systematic descriptive information on their classroom experiences. Systematic evidence on what pupils with SEND experience moment-by-moment, day-to-day, in terms of classroom contexts like class size and groupings, and interactions seems an essential basis to inform practice.

It was considered that the most useful way of obtaining the information needed was through close systematic observations to provide multiple data points and reliable estimates of frequencies of relatively easily observable categories of behaviours and contexts. We built on previous observation research by the authors (see method section).

Results from large scale UK classroom observation studies, such as ORACLE (Galton et al., 1999), School Matters (Mortimore et al., 1988), PACE (Pollard et al., 2000) and the Class Size and Pupil Adult Ratio project (Author 1 et al., 2003a), describe interactions and behaviour in the primary classroom, but are now dated and do not differentiate sufficiently between the experiences of pupils with and without SEND. An earlier observation study (Croll and Moses, 1985) was concerned with describing the behaviour and interactions of pupils with SEND and how these differed from pupils without SEND. Valuable though it is, this research represents a picture that is now more than 30 
years out of date. Author 2 (2015) provides an analysis of data from six large-scale systematic observation studies of primary-aged pupils with and without SEND, conducted between 1976 and 2012 , but this only focuses on the frequency of teacher-pupil and TA-pupil contact.

Overall, then, there is a paucity of systematic observation research on pupils with SEND from mainstream primary and secondary school settings. This paper reports for the first time observation data on the educational experiences of a cohort of pupils with SEND at two points in their school career (ages 9-10 and 13-14).

Research questions

Research question 1: what is the size of class as experienced by pupils with SEND vs typicallydeveloping pupils, in primary vs secondary schools.?

Research question 2: what is a. the composition of within class groupings in primary schools and $b$. classes at secondary school, in terms of the degree to which they are formed of similar high, average or low attainment, or mixed attainment?

Research question 3: what is the prevalence of interactions with teachers vs TAs vs other pupils for pupils with SEND vs typically-developing pupils, at primary vs secondary schools?

\section{Methodology}

The study comprised two phases. In the first phase, we collected data on 48 pupils in Year 5 (9-10 year olds) who had a Statement for either moderate learning difficulties (MLD) or behaviour, emotional and social difficulties (BESD). These categories of SEND were selected as they are commonly occurring, and were also likely to detect school support factors connected to problems with learning and classroom engagement. Other categories of SEND (e.g. hearing or visual impairment) were more likely to be affected by, and be seen by schools, in terms of within-pupil factors.

The research team, in collaboration with local authority (LA) staff, identified pupils who met the above criteria. We then approached the headteachers of the schools these pupils attended and headteachers then facilitated the process of securing permission from parents/carers and obtaining the necessary consents and ethical clearances. School visits were carried out over the 2011/12 school year.

In 2014, the SEND Code of Practice was revised. Statements began to be replaced by Education, Health and Care Plans (EHCPS), and the categories of SEND were reorganised under four broad areas of need. Pupils with MLD were subsumed under the category of cognition and learning, and BESD was removed altogether. So, for the second phase of data collection, to offer some consistency between the two cohorts, we prioritised the recruitment of pupils with needs relating to cognition and learning. The research team worked with LAs and the school's SEND coordinator (SENCO) to identify pupils in Year 9 (13-14 year olds) with a Statement/EHCP for cognition and learning. School visits were carried out between autumn 2015 and spring 2016.

In each phase, researchers shadowed pupils with Statements/EHCPs for between three and five days each over a school week. The multi-method approach to data collection combined systematic observations with data drawn from case studies involving interviews and observations. Findings from the case studies are presented in Author 2 and Author 1 (2013) and Author 2 and Author 1 
A small number of pupils $(n=5)$ had a somewhat more complex composition of needs, of which one of the main presenting needs was either MLD or BESD. Analyses indicated few differences between the three groups and so results were combined. At the point of the first phase of data collection, pupils with Statements for MLD and BESD comprised, respectively, $11 \%$ and $13 \%$ of all primary-aged pupils (e.g. aged 5-11) with Statements attending state-funded schools (DfE 2012a). Just under 10,000 pupils (17\%) of the 58,535 primary-aged pupils (aged 5-11) with Statements were in Year 5: $74 \%$ were boys; $26 \%$ were girls. Of all primary pupils with Statements, $78 \%$ were white and $22 \%$ identified as belonging to another ethnic group. As can be seen from Table 1, our Year 5 sample was consistent with this national picture. Pupils with Statements known to be eligible for free school meals (FSM) were over-represented ( $46 \%$ vs. $29 \%$ nationally) and pupils whose first language was other than English (EAL) were under-represented (6\% vs. 15\% nationally).

In the second phase of data collection, observations were made of 49 pupils who were in Year 9. Researchers visited fewer schools overall $(n=34)$, but there was a greater geographical spread. In addition to the regions from phase one, researchers went to secondary schools in the west Midlands, north-west England and Yorkshire and the Humber. All schools were comprehensives, and the majority (71\%) were located in predominantly urban areas. Pupil rolls ranged from 317 to 2,187, with most schools having between 1,000 and 1,299 pupils. In 25 schools there was one child, in 5 schools there were two per school, in 2 schools there were 3 per school, and in 2 schools there were 4 per school.

Most of these pupils at Year 9 (82\%) had a Statement/EHCP for needs relating to cognition and learning. Pupils with a Statement/EHCP relating to the categories of need prevalent within cognition and learning - MLD and severe learning difficulties (SLD) - together accounted for $16 \%$ of all pupils with Statements/EHCPs in mainstream secondary schools. In terms of representativeness, at January 2016 (during the second fieldwork phase), there were 50,884 pupils attending state-funded mainstream secondary schools with Statements/EHCPs (DfE, 2016b). Just under a fifth were in Year 9. Of these, $75 \%$ were boys and $75 \%$ were white British; $25 \%$ identified as being in another ethnic group. As the data in Table 2 show, our sample diverged marginally from these proportions. Pupils with Statements/EHCPs known to be eligible for free school meals were slightly over-represented in our sample ( $31 \%$ vs. $26 \%$ nationally), whilst EAL pupils were in line with the national picture ( $12 \%$ vs. $11 \%$ nationally). 
Table 1 about here

Table 2 about here

For efficiency, we began constructing the sample for the second phase of data collection by rerecruiting pupils who were involved in the first phase. We then added to this by recruiting pupils in LAs that were not previously involved in the study. In total, 19 pupils in the Year 9 sample also featured in the Year 9 sample (39\%). This means the design includes a small group observed twice, though this is unlikely to bias the broad cross age comparisons required.

\section{Comparison (non-SEND) pupils}

Observations were also collected on comparison pupils. The aim was to observe a sample of typically-developing pupils, average in the class in terms of their academic attainment, in order to provide a point of reference for the results on the pupils with Statements/EHCPs. In the first phase of data collection, primary teachers were asked to identify at least three average-attaining pupils in the class, and one of these pupils was used as the comparator for each lesson observation. These pupils were rotated to extend the numbers observed, but also to accommodate possible absences. Comparison pupils were matched to the pupils with Statements/EHCPs in terms of gender. Observations were collected on 151 control pupils: 115 boys and 36 girls.

In the second phase of data collection in secondary schools, anticipating that many secondary schools set pupils by attainment for these core subjects, researchers observed in classes the schools defined as 'average-attaining'. With guidance from the class teacher, researchers selected one average-attaining pupil to observe for the duration of the lesson. Comparison pupils were again matched in terms of gender to the pupil with the Statement, who was the primary focus of the school visit. Observations were collected on 112 average-attaining pupils, again matched by gender: 83 boys and 29 girls.

\section{Systematic observations}

Systematic observation allows researchers to take snapshots of the classroom at regular intervals, focusing on the observed behaviour of teachers and/or pupils. Analyses conducted on the large datasets provide a valuable objective insight into the main features of classroom life often unavailable to everyday experience or received opinion. Systematic observation is a technique not without its critics (Barrow, 1984; Delamont \& Hamilton,1986) or defenders (Croll, 1986; Mclntyre \& MacLeod, 1986). The strength of the method is its scale and limited susceptibility to inflection and interpretation by individual observers. It provides a relatively straightforward (though labour intensive) means of obtaining descriptive quantitative data, but the trade-off is that the pictures of classroom life painted using these data are typically achieved using broad strokes. It used a category system determined prior to data collection with explicit and rigorous definitions, and criteria for classifying behaviour and contexts.

The main systematic observation procedure was the same for all pupils in all schools. Researchers observed for the first ten seconds of each minute, then for the rest of the minute, coded the interactions, activities and contextual information in operation during those ten seconds. In primary schools, where pupils with and without SEND tended to be taught in the same class, researchers ensured that every fifth minute of each observation, the focus moved to the comparison pupil. 
Where observations of pupils with Statements/EHCPs took place away from the main classroom, contemporaneous data on comparison pupils could not be collected. The procedure was similar for the secondary sample, but observations on comparison pupils were made in classes the schools defined as 'average-attaining'.

The categories were low inference to ensure consistency and agreement between different observers. Researchers received a full day of training in the data collection approach, methods and tools, which was delivered the week before the fieldwork, along with practice experience at the start of field work. Observers recorded activities according to explicit decision rules, which formed a significant part of the training.

Researchers recorded contextual items at the start of each lesson observation. These were:

- Curriculum subject

- Class attainment: high, middle, low or mixed attainment (secondary only).

The number of pupils and adults present in the room were collected at five minute intervals, as these features of lessons tend to remain stable for longer periods.

The categories coded on the minute-by-minute basis were:

- Location: whether the pupil was in or away from the main classroom.

- Social mode of pupils' interactions. whether the pupil was interacting with a teacher, a TA, a classmate, or not interacting with anyone

- Interaction context: whether the interaction involving the pupil took place on a one-to-one basis, or as part of the class or a group

- Group attainment: attainment level (high, middle, low or mixed) of the group the pupil was in, as defined by the teacher (primary only).

Analyses are based on a large dataset, totalling 67,928 observations (data points), collected over 1,132 hours of observation. Researchers collected 57,467 observations (958 hours) of pupils with SEND: 30,782 (513 hours) in primary; 26,685 (445 hours) in secondary. As the main focus of each study was on the pupils with Statements/EHCPs, fewer observations were collected on comparison pupils. In total, 10,461 observations (175 hours) were collected on pupils without SEND: 4,233 (71 hours) in primary; 6,228 (104 hours) in secondary.

\section{Inter-rater reliability analysis}

In the first phase of data collection, the core team of three fieldworkers conducted two rounds of inter-rater reliability checks. The method involved the lead researcher (R1) spending half-a-day with each of the other researchers (R2 and R3), coding observations contemporaneously. Reliability coefficients (kappa) were calculated for the main mutually exclusive categories and examined the extent of agreement between the codes recorded by R1 and R2, and by R1 and R3. Each analysis was based on three hours of observation. Results showed a consistently high or very high agreement for the categories of social mode and group attainment, with kappa scores of 0.80 or higher.

One of the features of the second phase of data collection was that it involved a larger number of fieldworkers, the majority of whom were students on the Doctorate in Educational Psychology programme at institutions across England. This enabled us to collect data from a wider geographical area, and also contribute to training programmes for educational psychologists. Inter-rater reliability 
checks were based on the comparison of observations made between pairs of fieldworkers who shared a data collection visit to a school. In total, 22 fieldworkers (11 pairs) coded classroom observations contemporaneously in schools across the localities. Ten dual-coded lesson observations were selected for analysis: eight involving pupils with Statements/EHCPs; and two involving comparison (non-SEND) pupils. The analysis was based on a total of 7.5 hours of observation and calculated the level of agreement between the codes recorded by the first and second observer. The results for the two main observations variables were again consistently high, with average kappa scores of 0.81 both for social mode and for interaction level and context.

\section{Results}

We will present results in three sections in the following order: setting and within class groupings, class size and interactions with teachers and TAs.

1.Setting and within class groupings

We first look at the experiences of pupils in primary schools (see Table 3). At Y5, comparison and Statemented pupil were usually present in the same classrooms and we therefore recorded the attainment level of the groups pupils were working in within the classroom (low, average, high or mixed). When the pupils were not in a group, the coding defaulted to 'mixed', reflecting the mixed level of attainment of the whole class.

Table 3 about here

Table 3 shows that at Year 5 comparison pupils were particularly likely to be in mixed attainment groups, spending $95 \%$ of observations in such groups. Pupils with statements, on the other hand, spent less time - three quarters of all observations - in mixed attainment groups, and spend a quarter of their time $(24 \%)$ in groups of similarly low attaining pupils.

As described above, in secondary schools, pupils are often taught in classes organised in terms of attainment or 'ability', at least for core subjects. We could examine this precisely in terms of the amount of time comparison and mainstream pupils spent in high, average, low and mixed attainment sets, for different subjects (see Table 4).

Table 4 about here

We can see that comparison pupils were, as would be expected, most often taught in average attainment sets for English, mathematics and science (84\% of their time in English, 99\% of their time in mathematics, and all their time in science). Mixed attainment classes were more common for other subjects (e.g. humanities). Overall, average attaining pupils were taught in average attaining classes for $80 \%$ of all observations across all school subjects.

Turning to pupils with SEND, we can see from Table 4 that they experienced teaching in very different classes. Over all subjects, nearly two-thirds of all observations (64\%) of these pupils with Statements/EHCPs were made in low attainment sets. This proportion increases markedly when we look just at the core subjects. Pupils with Statements/EHCPs spent $85 \%$ of observations in English, $84 \%$ of their time in mathematics, and $83 \%$ of their time in science, being taught in low attainment sets. Relatively few of these pupils were taught in average attainment sets, and almost none in high attainment sets. Across all subjects, pupils with Statements/EHCPs were in mixed attainment classes in just under a third of observations (30\%). 
Table 5 about here

2. Class size

Researchers collected data on the number of pupils and adults in classrooms. As described in the introduction, these data allowed us to address class size in terms of the actual number of pupils in the class at any given moment rather than a more nominal and less accurate total taken from the class register.

In Table 5 we have set out the total class size data for comparison pupils and those with Statements/EHCPs in Year 5 alongside comparable data for Year 9 pupils. As described above, in Year 5 pupils tended not be in sets and so the class size is the same for both groups of pupils, while at Year 9 class sizes could vary for different sets. The clear finding is that in primary schools, average attaining and pupils with Statements/EHCPs were most often taught together in larger classes, within the range of 21 to 28 pupils ( $66 \%$ of observations). Just over one in five pupils at Year 5 (21\%) were taught in classes of 29 or over. By contrast, in Year 9, comparison pupils were taught in classes in the range 21 to 28 pupils for $56 \%$ of observations, and only $13 \%$ were in classes of 29 or over. Pupils with Statements/EHCPs at Year 9 were taught in the smallest classes $-23 \%$ within the range of 21 to 28 pupils and only $3 \%$ of observations in classes of 29 or over. By contrast, pupils with Statements/EHCPs were most often in smaller classes of 20 or less $-74 \%$ or 3 in 4 of observations.

For the Year 9 data we looked in more detail at whether the different attainment sets varied in their size; in other words, whether class size differed depending on attainment grouping. The results of this cross-tabulation are shown in Table 6. Comparison pupils tended to be taught in average attainment classes within the range of 17 to 28 pupils (76\% of observations). In contrast, the size of the classes in which pupils with Statements/EHCPs were taught tended to be much smaller. In the clear majority of observations (77\%), the low attainment classes in which pupils with SEND were taught comprised 16 or fewer pupils. In just over half of cases (55\%), these pupils were in classes of 12 or fewer pupils.

Table 6 about here

3.Interactions with adults and peers in the classroom

We first examined the numbers of teachers and TAs during observations at Year 5 in primary schools. As comparison pupils and those with Statements/EHCPs spent most of their time in the same classroom, the data are for all pupils together. In three in four observations (73\%) there was one teacher and at least one TA present. What we might call the historical, traditional arrangement of one teacher alone in a classroom occurred in only $14 \%$ of observations. By way of contrast, in the majority of observations (75\%) for average attaining pupils in Year 9 , there was just one adult present: the teacher. In a quarter of observations, a TA was also present. However, the opposite is true for pupils with Statements/EHCPs. Similar to the primary school data, in three-quarters of observations (76\%) there at least one TA, with only a quarter of observations involving just one teacher.

Putting the data on class size and adults together for Year 9 pupils, we can conclude that average attaining pupils were generally taught in homogenous, average attainment classes by one teacher, 
whereas pupils with Statements/EHCPs tended to be taught in much smaller homogenous, low attainment classes with a teacher and one TA in the room.

Table 7 about here

In order to provide a comprehensive view of the interactions of pupils with and without SEND, we constructed a table drawing together all the observation data on interaction categories. The table is structured around three key 'social modes': pupils interacting with adults (teachers or TAs); pupils interacting with their classmates; not interacting with anybody. These three social modes are mutually exclusive (i.e. only one can be coded at any time) and comprehensive (i.e. they cover all observations that were made).

Table 7 presents the data for these three social modes for the comparison pupils and those with Statements/EHCPs. In addition, the adult-pupil interaction social mode is further divided into whether these interactions involved teachers or TAs, and, further still, whether each of these types of interaction occurred as part of the whole class, part of a group or on a one-to-one basis. The observations of comparison pupils only took place in the classrooms (these pupils are not routinely withdrawn from lessons), but observations for pupils with Statements/EHCPs are divided into whether the location occurred in classroom or outside the classroom.

There are some obvious similarities in how time was distributed between the three social modes for the average attaining pupils. In Year 5, average attaining pupils interacted with teachers in $40 \%$ of observations, $2 \%$ with TAs, $32 \%$ with peers, and $26 \%$ not interacting. Results for Year 9 were broadly similar: average attaining pupils were interacting with teachers in about half of all observations $(47 \%)$, interacting very little with TAs (1\%), and in a quarter of observations each they were interacting with peers (27\%) and not interacting (26\%). The results, therefore, indicate that the quantity of interactions in the three social modes are similar for average attaining pupils across the primary and secondary phases.

There were more obvious differences in the experiences of pupils with Statements/EHCPs across the two time points. At Year 5, a substantial minority of observations occurred away from the classroom (27\%). In contrast the vast bulk of observations at Year 9 took place in the classroom (96\% vs. 4\% out of class), and, in this respect, were similar to average attaining pupils.

Turning now to time in the three social modes, at Year 5 pupils with SEND spent $26 \%$ of observations interacting with the teacher; $15 \%$ with TAs; $13 \%$ with peers; and 19\% not interacting. In contrast, at Year 9, pupils with SEND spent $42 \%$ of observations interacting with teachers, 15\% with TAs, 16\% with their classmates, and $23 \%$ not interacting. So, by Year 9 , the balance had shifted to a greater proportion of interactions with teachers in classrooms, while there were the same percentage of observations with TAs. There was not, therefore, as great a difference as at Year 5 in the amount of interactions pupils with SEND had with their teachers in class, compared to average attaining pupils (Year 5: 26\% vs. 40\%; Year 9: 42\% vs. 47\%).

Across both time points it was clear that pupils with SEND spent less time interacting with their classmates in comparison to pupils without SEND (Year 5: $18 \%$ vs. 32\%; Year 9: 16\% vs. 27\%). It seems as if the higher number of interactions with TAs occurs at the expense of interactions with peers, and to a lesser extent, with teachers.

The overall balance of whether interactions with teachers and TAs were as part of the class, part of a group or on a one-to-one basis were similar across Year 5 and Year 9 for both pupils with and 


\section{Class size and SEND}

The situation that emerges from the Year 5 data with respect to class size is troubling, and counter to what is observed in education systems elsewhere in the world. The UK is unusual in having larger class sizes at primary school level than at secondary school level. One might have expected that, pedagogically speaking, it would make more sense for the younger pupils to be in smaller classes. But the situation that emerges from the present study is even more troubling, in that pupils with SEND in primary schools are in much larger classes than they experience in Year 9. If it is true that pupils with SEND are in general most effectively taught in smaller classes, then one might ask why wait until their third year of secondary schooling before educating pupils in such small classes?

One strategy that might be adopted when faced with the problem of large classes is the use of whole class teaching, and indeed observation research shows this is a common approach (Author 2, 2015). Whatever the overall benefits of whole class teaching - and this is the subject of debate (Kyriacou, 2009) - it is much less likely to be appropriate for pupils with SEND, who often have particular difficulties in following instructions. They are bound to need a more individualised educational support, and teachers face considerable problems in providing the necessary differentiation and time in large classes (Author 2 \& Author 1, 2017).

The findings suggest that class size is 'the elephant in the room' when it comes to the inclusion of pupils with SEND in mainstream schools. Evidence from Author 1 and Russell (in prep.) is that large class sizes at primary level will always make the inclusion of pupils with SEND problematic, e.g., because large classes make it more difficult to provide necessary differentiation and individual support Sometimes the role of class size is seen as a binary choice: either invest in small classes or 
the quality of teaching. But this is a false choice. Of course, the most important thing is to develop informed teaching strategies for pupils and a trained workforce, but educating such pupils in large classes makes already challenging classroom management and teaching decisions much more difficult. The policy implication is that wherever possible children with SEN should be taught in smaller classes.

2. The composition of within class groups and class level sets in terms of ability or attainment mix

A common classroom organisation strategy at primary level - perhaps especially when faced with a large class and diversity of attainment - is the setting up of within class groupings, usually based on attainment level. The supposed benefits of this arrangement are rarely articulated in a formal and rigorous way, despite its popularity. We have seen that for much of their time pupils with SEND are taught in groups with other pupils with SEND or low attaining pupils. Though this study is not able to comment on the quality and challenge of work undertaken in these groups, one consequence of this arrangement is that pupils with SEND become separated from their classmates, and have a reduced number of interactions with them. Moreover, pupils in such groups are often supported by TAs rather than the teacher (see also Author 1 et al., 2012).

The classroom organisation strategy in secondary schools was different, with pupils allocated and taught in separate classes for certain subjects on the basis of their attainment. We have seen that young people with SEND are likely to be allocated to smaller lower attainment sets. In effect, what is happening in mainstream secondary settings is very like 'streaming', which was common in schools in the 1950s and 1960s; that is, children are being taught in a different class for most of their time and school subjects, with this allocation made on the basis of a judgement about their level of attainment, usually on or soon after their entry into the school.

Given concerns about large class sizes at primary school, described above, the smaller set sizes for pupils with SEND might be seen as a positive arrangement. However, studies reviewed in the introduction raise concerns about setting by 'ability', e.g., in terms of the level of curriculum and instructional challenge in these low attaining sets and the danger of expectations and judgements about academic attainment being reinforced through this method of classroom organisation and allocation. Moreover, some Year 9 pupils felt there was a stigma attached to being in the 'bottom sets' (Author 2 \& Author 1, 2017). This discussion raises important questions about expectations, teaching strategies, curriculum level and learner motivation and identities which cannot be addressed here. One direction for future research would be closer exploration of the educational experiences within these sets, and what role they play in pupils' longer term educational progress.

\section{The amount and type of interaction with teachers, TAs and peers}

Taking results from Year 5 and 9 together, TAs are a consistent and central feature of the educational experiences of pupils with Statements/EHCPs in both primary and secondary schools. While the proportion of time pupils with SEND interact with TAs reduces when in Year 9, it nonetheless accounts for around one-fifth of all their interactions, and outweighs interactions with classmates. There was then a high reliance on and use of one-to-one TA support in both primary and secondary settings. It is difficult to avoid the conclusion that primary and secondary schools view the employment and deployment of TAs as a key strategic approach to including and meeting the educational needs of pupils with SEND. Given problems with this arrangement in the UK in terms of pupil academic progress (Author 1 et al., 2012), as well as concerns about the inappropriate use of para-professionals in the education of pupils with SEND in the USA (Giangreco, Yuan, McKenzie, 
Cameron \& Fialka, 2005), we suggest that school staff are mindful of institutional arrangements and classroom practices that result in pupils with Statements/EHCPs having less time with teachers, relative to other pupils. Elsewhere we have developed guidance for the deployment of TAs, which includes working with pupils with SEN (Author 2, Russell \& Author 1, 2016).

\section{Conclusions}

Putting together key results on class size, composition of adults and attainment grouping, we find that at Year 5 pupils with SEND spend over a quarter of their time away from the mainstream class, class teacher and their peers. When they worked in groups, it was mostly with other pupils identified as low-attaining and/or as having SEND. In mainstream secondary schools, the educational experiences of pupils with Statements/EHCPs are characterised by being taught in small homogenous, low-attaining classes, with at least one TA present. Their average-attaining peers, meanwhile, are taught in larger homogenous classes, with just the teacher present.

Observation results therefore show that in primary schools, pupils with SEND experienced a high degree of separation from the classroom, teacher and peers, and in secondary settings we found a form of segregation, with lower-attaining pupils and those with SEND taught alongside one another, separately from their average- and higher-attaining peers. The rationale for these organisational arrangements is ostensibly to assist struggling pupils, but the unintended consequences may require a careful rethink of classroom contexts for learning in primary and secondary schools.

The aim of this study was to obtain a detailed picture, built up on the basis of a high number of moment by moment observations, of the classroom contexts for learning for pupils with SEND, in comparison to average attaining pupils. In particular, the study focused on three main features: class size, grouping arrangements within and across classes, and the interactions with teachers, TAs and other pupils. In our view this information, though often overlooked, is a key influence on the quality and appropriateness of education provided for pupils. Teaching methods and curriculum and assessment arrangements are clearly important but it is also important to know about the classroom contexts within which they and ultimately pupil learning take place. Classroom learning contexts may serve to facilitate or inhibit pedagogical approaches. One may, for example, seek to help pupils with SEND by maintaining sustained one to one input from the teacher, but this may not be possible when a teacher has to also manage a large class with pupils with diverse needs.

Earlier we cited the value of an ecological approach to school learning, drawing on the early work of Bronfenbrenner (1979) and Barker and Gump (1968), but our work for this paper suggests we need to take this further and develop a view of classroom effects on learning that recognises and seeks to capture the interconnected nature of the contextual, interactive, and pedagogical features at work. We argue that class size, for example, is best conceived as a context for teaching and learning that interconnects with other classroom contextual features like within class groupings. It is these interconnections, and, in particular, the way that teachers manage the class size and groups in the class, which are the key factor when considering effects on educational outcomes. Author 1 , Kutnick, Baines, and Galton (2003) coined the term 'social pedagogy' to help show how learning in schools is not simply the result of teachers exerting an influence on pupils but that learning takes place in a distinct physical and social setting within which complex, multiple decisions are taken about how to best coordinate and manage the various factors involved, including class size. This was taken further by Kutnick and Author 1 (2014) and is currently being developed by one of the authors in a book length treatment (Author $1 \&$ Russell, in preparation). The search for the interconnections between 
classroom contextual factors and classroom interactions is important conceptually but also in terms of policy and practice.

Acknowledgement: The authors are grateful to the Nuffield Foundation for funding the two projects reported in this paper. They also wish to thank the fieldworkers, the school staff who helped secure informed consent from families, and the expert group of professionals, practitioners and researchers with whom we shared our emerging findings and reflections.

\footnotetext{
${ }^{\mathrm{i}}$ Corresponding author:
}

\section{References}

Ainscow, M. (2007) From special education to effective schools for all: A review of the progress so far, in L. Florian (Ed) (2009) The SAGE handbook of special education (London: SAGE), 146-159

Alexander, R. (Ed) (2009) Children, their world, their education: Final report and recommendations of the Cambridge Primary Review (London: Routledge).

Alexander, R., Rose, J. \& Woodhead, C. (1992) Curriculum Organisation and Classroom Practice in Primary Schools: a discussion paper (London, DES)

Baines, E., Author 1, \& Kutnick, P. (2003) Changes in grouping practices over primary and secondary school. In Author 1 \& P. Kutnick (Eds) Special Edition of International Journal of Educational Research, 39, 9-34

Barker, R. \& Gump, P. (1964) Big School Small School (Stanford: Stanford University Press). Barrow, R. (1984) The logic of systematic classroom research: The case of Oracle, Durham and Newcastle Research Review, 10 (53).

Biddle, B.J., \& Berliner, D.C. (2002) Small class size and its effects, Educational Leadership, 5 (5), 12 23. (Longer review in: Biddle, B.J. \& Berliner, D.C. (2002). What research says about small classes and their effects. Part of series In pursuit of better schools: What research says. Downloadable from www.WestEd.org/policyperspectives or http://edpolicyreports.org )

Author 1. (2003) The class size debate: Is small better? (Maidenhead: Open University Press).

Author 1. (2012) Three generations of research on class size effects. In K.R. Harris, S. Graham \& T. Urdan (Eds), The American Psychological Association (APA) Educational Psychology Handbook. Vol. 2 Individual Differences and Cultural and Contextual Factors (Washington, DC: American Psychological Association), 529-554.

Author 1, Baines, E., Kutnick, P. \& Martin, C. (2001) Classroom contexts: connections between class size and within class grouping, British Journal of Educational Psychology, 71(2), 283-302.

Author 1, Bassett, P. \& Brown, P. (2005) Teachers' and pupils' behaviour in large and small classes: a systematic observation study of pupils aged 10/11 years, Journal of Educational Psychology, 97(3), 454-467. 
Author 1, Bassett, P. \& Brown, P. (2011) Examining the effect of class size on classroom engagement and teacher-pupil interaction: differences in relation to prior pupil attainment and primary vs. secondary schools, Learning and Instruction, 21, 715-730

Author 1, Bassett, P., Goldstein, H. \& Martin. C. (2003) Are class size differences related to pupils' educational progress and classroom processes? Findings from the Institute of Education Class Size Study of children aged 5-7 Years, British Educational Research Journal, 29(5), 709-730. Special Issue 'In Praise of Educational Research', Guest Editors: S. Gorrard, C. Taylor and K. Roberts.

Author 1, Kutnick, P., Baines, E. \& Galton, M. (2003) Toward a social pedagogy of classroom group work. In P. Author 1 \& P. Kutnick (Eds) Special Edition of International Journal of Educational Research, 39, 153-172.

Author 1, Russell, A. \& Author 2. (2012) Reassessing the Impact of Teaching Assistants: How Research Challenges Practice and Policy (Oxon: Routledge).

Author 1, \& Russell, A. (in prep.) Class Size and Effective Teaching

Bronfenbrenner, U. (1979) The Ecology of Human Development (Cambridge, MA: Harvard University Press).

CACE (1967) 'The Plowden Report' Children and Their Primary Schools Vol 1 Central Advisory Council for Education(England) (London: HMSO)

Creemers, B. (1994) The Effective Classroom (London: Cassell).

Croll, P. (1986) Systematic Classroom Observation (London: Falmer).

Croll, P. \& Moses, D. (1985) One in five: the assessment and incidence of special education needs (London: Routledge and Kegan Paul).

Delamont, S., \& Hamilton, D. (1986). Revisiting classroom research: A continuing cautionary tale. In M. Hammersley (Ed.) Controversies in Classroom Research (Milton Keynes, England: Open University Press), 25-43

Dept. for Education (2016a) Special Educational Needs: An Analysis and Summary of Data Sources, London, DfE.

Dept. for Education (2016b) Special educational needs in England: January 2016. Available online: https://www.gov.uk/government/statistics/special-educational-needs-in-england-january-2016. Accessed on 17.04.17.

Ehrenberg, R.G., Brewer, D.J., Gamoran, A. \& Willms, J.D. (2001) Class size and student achievement, Psychological Science in the Public Interest, 2 (1), 1-30.

Finn, J.D., Pannozzo, G.M. \& Achilles, C.M. (2003). The 'why's' of class size: student behaviour in small classes. Review of Educational Research, 73(3),321-368

Florian, L. (Ed) (2009) The SAGE handbook of special education (London: SAGE), 146-159. 
Francis, B., Archer, L., Hodgen, J., Pepper, D., Taylor, B. \& Travers, M.C. (2017) Exploring the relative lack of impact of research on 'ability grouping' in England: A discourse analytic account, Cambridge Journal of Education, 47(1), pp, 1-17.

Galton, M.J., Hargreaves, L., Comber, C., Wall, D. \& Pell, A. (1999) Inside the primary classroom: 20 years on (London: Routledge).

Gersten, R. \& Edwards Santoro, L. (2009) Advances in research on teaching students who experience difficulties in learning: grappling with the issue of access to the general curriculum, in L. Florian (Ed) The SAGE handbook of special education (London: SAGE), 187-206.

Giangreco, M.F., Yuan, S., McKenzie, B., Cameron, P. and Fialka, J. (2005) Be careful what you wish for...': Five reasons to be concerned about the assignment of individual paraprofessionals, Teaching Exceptional Children, 37(5), 28-34.

Ireson, J., Hallam, S., Hack J., Clark, H. \& Plewis, I. (2002) Ability grouping in English secondary schools: effects on attainment in English, mathematics and science, Educational Research and Evaluation, 8(3), 299-318.

Kounin, J.S. \& Gump, P.V. (1974) Signal systems of lesson settings and the task-related behaviour of pre-school children, Journal of Educational Psychology, 6 (4), 554-562.

Kutnick, P., \& Author 1, (2014) Effective Group work in Primary School Classrooms: the SPRinG approach (Dordrecht: Springer).

Kutnick, P., Sebba, J., Author 1, Galton, M., Thorpe, J., Maclntyre, H. \& Berdondini, L. (2005) The Effects of Pupil Grouping: Literature Review. Research Report 688 (London: Dept. for Education and Skills)

Kyriacou, C. (2009) Effective Teaching in Schools: Theory and Practice (Cheltenham, UK: Nelson Thornes).

McIntyre, D., \& Macleod, G. (1986) The characteristics and uses of systematic observation. In M. Hammersley (Ed), Controversies in classroom research (Milton Keynes, England: Open University Press).

Mortimore, P., Sammons, P., Stoll, L., Lewis, D. \& Ecob, R. (1988) School matters: The junior years (Wells: Open Books).

Muijs, D., \& Reynolds, D. (2011. Effective Teaching: Evidence and Practice. $3^{\text {rd }}$ Edition. (London: Sage).

O’Brien, J. (2016) Don't Send Him in Tomorrow (Carmarthen: Independent Thinking Press).

Peacock, A. (2016) Assessment for Learning without Limits (Maidenhead: Open University Press).

Pollard, A., Broadfoot, P., Croll, P., Osborn, M, \& Abbott, D (1994) Changing English Primary Schools? The Impact of the Education Reform Act at Key Stage One (London and New York: Cassell)

Taylor, B., Francis, B., Archer, L., Hodgen, J., Pepper, D., Tereshchenko A. \& Travers, M-C. (2016) Factors deterring schools from mixed attainment teaching practice, Pedagogy, Culture and Society, DOI: 10.1080/14681366.2016.1256908. 
Author 2. (2015) The classroom experiences of pupils with special educational needs in mainstream primary schools - 1976 to 2012. What do data from systematic observation studies reveal about pupils' educational experiences over time?, British Educational Research Journal, 41(6), 992-1009

Author 2, \& Author 1. (2015) Worlds apart? The nature and quality of the educational experiences of pupils with a statement for special educational needs in mainstream primary schools, British Educational Research Journal, 41(2), 324-342.

Author 2, \& Author 1. (2017) The Special Educational Needs in Secondary Education (SENSE) study. Final Report.

Author 2. \& Author 1. (2018) Making sense of 'teaching', 'support' and 'differentiation': the educational experiences of pupils with Education, Health and Care Plans and Statements in mainstream secondary schools, European Journal of Special Educational Needs. DOI:

10.1080/08856257.2018.1458474

Author 2, Author 1, Bassett, P., Brown, P., Martin, C. \& Russell, A. (2010) Double standards and first principles: Framing teaching assistant support for pupils with special educational needs, European Journal of Special Needs Education, 25(4) 319-336.

Author 2, Russell, A., and Author 1. (2016) Maximising the impact of teaching assistants: guidance for school leaders and teachers. $2^{\text {nd }}$ Edition. Abingdon, Oxon, UK: Routledge 